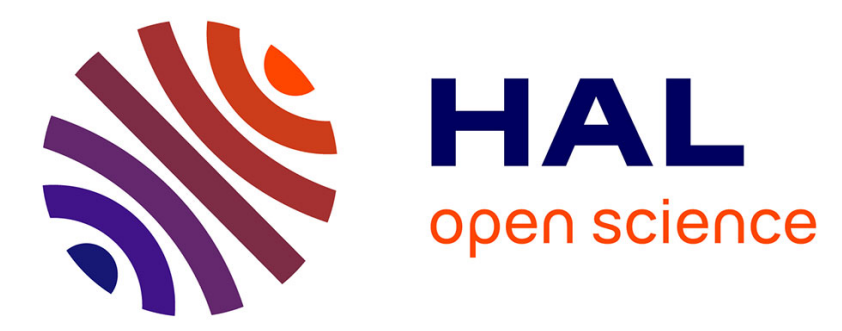

\title{
Effects of the Amount of Fillers and of the Crosslink Density on the Mechanical Behavior of Carbon-Black Filled Styrene Butadiene Rubbers
}

Yannick Merckel, Julie Diani, Mathias Brieu, Julien Caillard

\section{- To cite this version:}

Yannick Merckel, Julie Diani, Mathias Brieu, Julien Caillard. Effects of the Amount of Fillers and of the Crosslink Density on the Mechanical Behavior of Carbon-Black Filled Styrene Butadiene Rubbers. Journal of Applied Polymer Science, 2013, 129, pp.2086-2091. 10.1002/app.38925 . hal-00996697

\section{HAL Id: hal-00996697 \\ https://hal.science/hal-00996697}

Submitted on 26 May 2014

HAL is a multi-disciplinary open access archive for the deposit and dissemination of scientific research documents, whether they are published or not. The documents may come from teaching and research institutions in France or abroad, or from public or private research centers.
L'archive ouverte pluridisciplinaire HAL, est destinée au dépôt et à la diffusion de documents scientifiques de niveau recherche, publiés ou non, émanant des établissements d'enseignement et de recherche français ou étrangers, des laboratoires publics ou privés. 


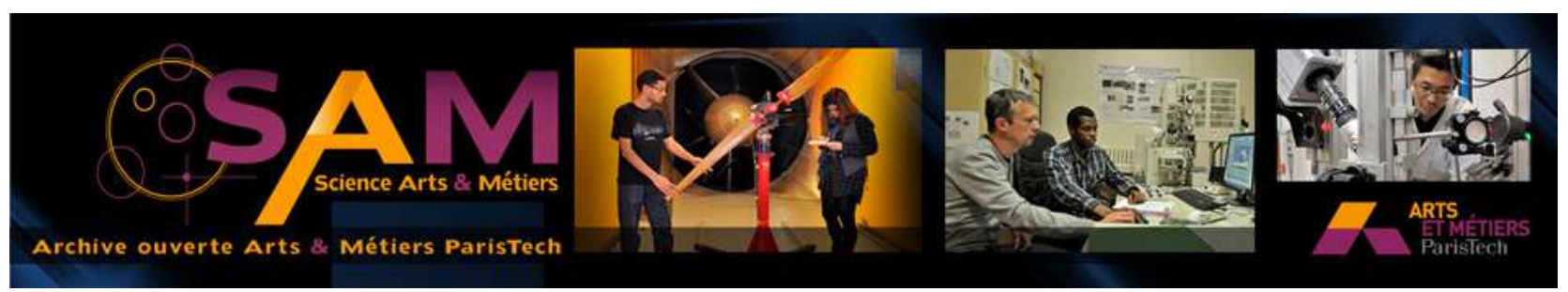

\section{Science Arts \& Métiers (SAM)}

is an open access repository that collects the work of Arts et Métiers ParisTech researchers and makes it freely available over the web where possible.

This is an author-deposited version published in: http://sam.ensam.eu

Handle ID: .http://hdl.handle.net/10985/8196

\section{To cite this version :}

Yannick MERCKEL, Julie DIANI, Mathias BRIEU, Julien CAILLARD - Effects of the Amount of Fillers and of the Crosslink Density on the Mechanical Behavior of Carbon-Black Filled Styrene Butadiene Rubbers - Journal of Applied Polymer Science - Vol. 129, p.2086-2091 - 2013 


\title{
Effects of the Amount of Fillers and of the Crosslink Density on the Mechanical Behavior of Carbon-Black Filled Styrene Butadiene Rubbers
}

\author{
Yannick Merckel, ${ }^{1}$ Julie Diani, ${ }^{2}$ Mathias Brieu, ${ }^{1}$ Julien Caillard ${ }^{3}$ \\ ${ }^{1}$ LML, Ecole centrale de Lille, bd Paul Langevin, 59650 Villeneuve d'Ascq, France \\ 2PIMM, CNRS, Arts et Métiers parisTech, 151 bd de l'Hôpital, 75013 Paris, France \\ ${ }^{3}$ Manufacture Française des Pneumatiques Michelin, CERL, Ladoux, 63040 Clermont-Ferrand, France \\ Correspondence to: J. Diani (E-mail: julie.diani@ensam.eu)
}

\begin{abstract}
Several carbon-black filled styrene-butadiene rubbers are subjected to monotonic uniaxial tension tests in order to investigate the effects of the amount of fillers and of the crosslink density on their mechanical properties. The Young modulus, the volume changes associated with material damage and the stretch to failure are extracted and discussed. Results compare well to the literature results when exist and quantitative analysis are proposed when possible. Results show that filled rubbers are not incompressible when submitted to uniaxial tension tests and their volume changes are strongly dependent of the amount of fillers but are unaffected by the crosslink density. The latter shows strong impact on the filled rubbers stretch to failure but more interestingly this impact is comparable to what is encountered in unfilled rubbers. The stretch to failure is improved by the addition of fillers with an optimum for material filled around $30 \mathrm{phr}$.
\end{abstract}

KEYWORDS: Rubber; properties and characterization; mechanical properties; elastomers; crosslinking

\section{INTRODUCTION}

A wide variety of filled rubbers is used in industrial and research fields. Several contributions highlight the impact of the filled rubber composition on their mechanical behavior. However, the relationship between the rubber composition and its mechanical response remains an ongoing issue. The current contribution investigates the effect of the amount of fillers and of the crosslink density on the mechanical responses of carbonblack filled styrene-butadiene rubbers (SBR) subjected to monotonic uniaxial tension up to failure. For this purpose, several materials manufactured with the same rubber gum and the same type of fillers are compared. They vary from each other in the amount of fillers or the crosslink density only.

Adding fillers is known to increase the material stiffness (see review $^{1}$ ), increase its Mullins softening, ${ }^{2}$ and delay its fracture in monotonous loading ${ }^{3}$ as in fatigue. ${ }^{4}$ Increasing the crosslink density is known to decrease the stretch to failure ${ }^{5}$ and the fatigue resistance. ${ }^{6}$ In order to propose a systematic analysis of these effects, a large set of materials was manufactured allowing us to quantitatively study the effect of the amount of fillers and of the crosslink density on the Young modulus, the damage and the stretch to failure undergone by non-crystallizing filled rubbers when subjected to monotonic uniaxial tension tests.

\section{MATERIAL AND EXPERIMENTS}

\section{Materials}

For this study, several vulcanized SBR filled with N347 carbonblack fillers were manufactured by Michelin (Ladoux, France). The material strategy is to vary the filler volume fraction and the crosslink density in order to investigate the effect of both parameters on the material mechanical behavior. The SBR gum is a random copolymer with a $15 \%$ styrene molar fraction. The crosslinking reaction using a classical crosslinking system based on sulfur and N-cyclohexyl-2-benzothiazolesulphenamide (CBS) is activated by zinc oxide and stearic acid. Finally, 6PPD antioxidant ( $\mathrm{N}$ (1,3-dimethyl-butyl)- $\mathrm{N}^{\prime}$-phenyl-P phenylenediamine) is added. The filler morphology is characterized by the fineness of elementary particles and by the aggregate structure. Fineness was measured close to $90 \mathrm{~m}^{2} \mathrm{~g}^{-1}$ by nitrogen absorption using Brunner-Emmet-Teller analysis. Aggregate structure was measured at $120 \mathrm{~mL} / 100 \mathrm{~g}$ by dibutyl phthalate (DBP) adsorption. Material compositions are listed in Table I.

Figure 1 illustrates the material strategy. Materials C1-C6 are of the same composition except for the amount of fillers varying from 0 to $60 \mathrm{phr}$ resulting in volume fractions varying from 0 to $23 \%$. From material C4 filled at $40 \mathrm{phr}$, materials A4, B4, D4, and E4 are obtained by varying the crosslink density only. 
Table I. Material Compositions in Parts Per Hundred (phr)

\begin{tabular}{lcrrrrrrrrr}
\hline Ingredient & \multicolumn{1}{l}{ A4 } & \multicolumn{1}{c}{ B4 } & \multicolumn{1}{c}{ C4 } & \multicolumn{1}{c}{ D4 } & \multicolumn{1}{c}{ E4 } & \multicolumn{1}{c}{ C1 } & C2 & C3 & C5 & C6 \\
\hline SBR & 100 & 100 & 100 & 100 & 100 & 100 & 100 & 100 & 100 & 100 \\
N347 carbon-black & 40 & 40 & 40 & 40 & 40 & 0 & 5 & 30 & 50 & 60 \\
Antioxidant (6PPD) & 1.9 & 1.9 & 1.9 & 1.9 & 1.9 & 1.9 & 1.9 & 1.9 & 1.9 & 1.9 \\
Stearic acid & 2.0 & 2.0 & 2.0 & 2.0 & 2.0 & 2.0 & 2.0 & 2.0 & 2.0 & 2.0 \\
Zinc oxide & 2.5 & 2.5 & 2.5 & 2.5 & 2.5 & 2.5 & 2.5 & 2.5 & 2.5 & 2.5 \\
Accelerator (CBS) & 4.7 & 2.3 & 1.6 & 1.2 & 1.0 & 1.2 & 1.2 & 1.2 & 1.2 & 1.2 \\
Sulfur & 4.7 & 2.3 & 1.6 & 1.2 & 1.0 & 1.2 & 1.2 & 1.2 & 1.2 & 1.2 \\
\hline
\end{tabular}

Michelin measured the material crosslink densities by swelling using the Flory-Rehner theory and the filler volume fractions are calculated with the component densities. Crosslink densities and filler volume fractions characterization of the materials are reported in Table II.

\section{Experiments}

Materials are subjected to monotonic uniaxial tension tests conducted on an Instron 5882 testing machine operating at room temperature. Normalized dumbbell samples with initial crosssection $S_{0}=4 \times 2.5 \mathrm{~mm}^{2}$ and $30 \mathrm{~mm}$ length are subjected to the tension tests. All tests are run at a constant crosshead speed of $10 \mathrm{~mm} \mathrm{~min} \mathrm{~min}^{-1}$. The force $F$ is measured by a $2 \mathrm{kN}$ load cell and the nominal stress is defined by $F / S_{0}$. Local stretches are acquired by video extensometry during stretching. For this purpose, a classic video extensometer detecting the motion of the centers of four marks was developed in-lab. The technique can detect the position of a mark center with a precision providing very satisfactory accuracy (below $10^{-2}$ ) for stretch measurements. In-plane stretches are computed using the motion of four marks painted on the sample free faces. The stretch in the tensile direction is noted by $\lambda$. Regular procedure uses one camera only facing one of the sample free face but in order to evaluate volume changes during stretching, two cameras are used, each one of them facing one orthogonal sample free face. With both cameras, one can access the three principal stretches $\lambda_{i}$.

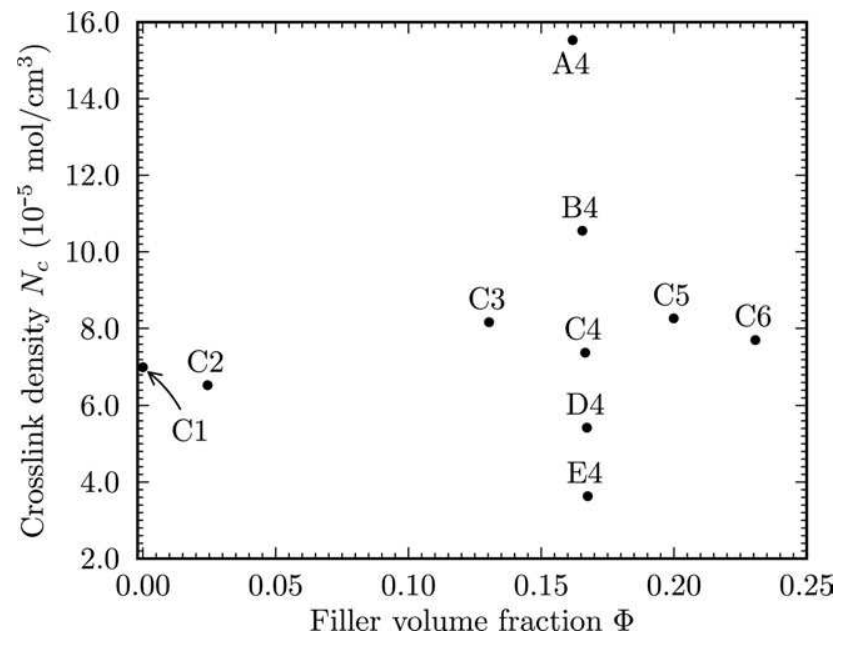

Figure 1. Material strategy.
Illustration of the stress-stretch responses obtained during the uniaxial tension tests is presented in Figure 2. The effect of the filler volume fraction on the stress-stretch responses is shown in Figure 2(a), which compares the responses of materials $\mathrm{C1}-$ C6. One may recognize the strong impact of the filler amount on the material stress-stretch responses. ${ }^{7-10}$ The effect of the crosslink density is shown in Figure 2(b) by comparing materials A4 to E4. Results show a strong impact of the crosslink density with a catastrophic fall of the rubber stretch ability when increasing the crosslink density above $15 \times 10^{-5} \mathrm{~mol} \mathrm{~cm}^{-3}$.

From these experiments, we extract and discuss the material's Young modulus, the volume changes associated with material damage and the stretch to failure. The Young modulus characterizes the material's response to a uniaxial tension at infinitesimal strain. It may be estimated by calculating the tangent modulus according to $E=\left.\frac{d \sigma}{d \lambda}\right|_{\sigma=0}$ or equivalently by approaching the stress-stretch response by a Neo-Hookean stress-stretch response $\sigma=\left.(E / 3)\left(\lambda^{2}-\lambda^{-1}\right)\right|_{\lambda=1}$. The Young modulus was calculated by the tangent modulus estimate calculated for small strain corresponding to stresses ranging between 0 and $0.2 \mathrm{MPa}$. The volume change is computed as the current volume $V$ over the initial volume $V_{0}\left(V / V_{0}=\lambda_{1} \lambda_{2} \lambda_{3}\right)$ and the stretch to failure is the maximum stretch $\lambda$. In order to present representative average values of the Young modulus and of the stretch to failure, each material was subjected to five uniaxial tension tests.

\section{RESULTS AND DISCUSSION}

\section{Young Modulus}

When applying uniaxial tension tests to a material, the first mechanical property that one measures is the Young modulus. Even though filled rubbers are mostly used in large deformation, one may find in the literature a substantial amount of work focusing on the Young modulus and studying its dependency to the amount of fillers. Authors attempted to relate the filled rubber Young modulus $(E)$ to the unfilled rubber Young modulus $\left(E_{g}\right)$, the amount of fillers, and filler structural parameters optionally. A rather complete review on the topic may be found in Ref. 8. One well known model is from Guth and Gold ${ }^{11}$ :

$$
E=E_{g}\left(1+2.5 \phi_{e f f}+14.1 \phi_{e f f}^{2}\right)
$$

with $\phi_{\text {eff }}$ the effective volume fraction of fillers in the rubber gum. Actually, in filled rubbers, the amount of effective volume 
Table II. Filler Volume Fraction $\phi$ and Crosslink Density $\mathrm{N}_{\mathrm{c}}$ for Each Material

\begin{tabular}{|c|c|c|c|c|c|c|c|c|c|c|}
\hline Material & A4 & B4 & C4 & D4 & E4 & C1 & $\mathrm{C} 2$ & C3 & C5 & C6 \\
\hline$\phi(\%)$ & 16.2 & 16.5 & 16.7 & 16.7 & 16.8 & 0 & 2.4 & 13.0 & 20.0 & 23.1 \\
\hline$N_{c}\left(10^{-5} \mathrm{~mol} \mathrm{~cm}^{-3}\right)$ & 15.5 & 10.6 & 7.4 & 5.4 & 3.6 & 7.0 & 6.5 & 8.2 & 8.3 & 7.7 \\
\hline
\end{tabular}

fraction of fillers is larger than the actual amount of fillers due to rubber gum trapped in branched structure of the filler aggregates. This trapped rubber is often referred as occluded rubber. In order to estimate $\phi_{\text {eff }}$, Medalia ${ }^{12}$ conducted DBP adsorption measures and proposed the following analytical solution fitted on its experiments:

$$
\phi_{\text {eff }}=\frac{\phi}{2}\left(1+\frac{1+0.02139 D B P}{1.46}\right)
$$

This relation is now commonly used, even though it becomes phenomenological for materials different (other fillers or other gum) from Medalia's material. We have tested the combination
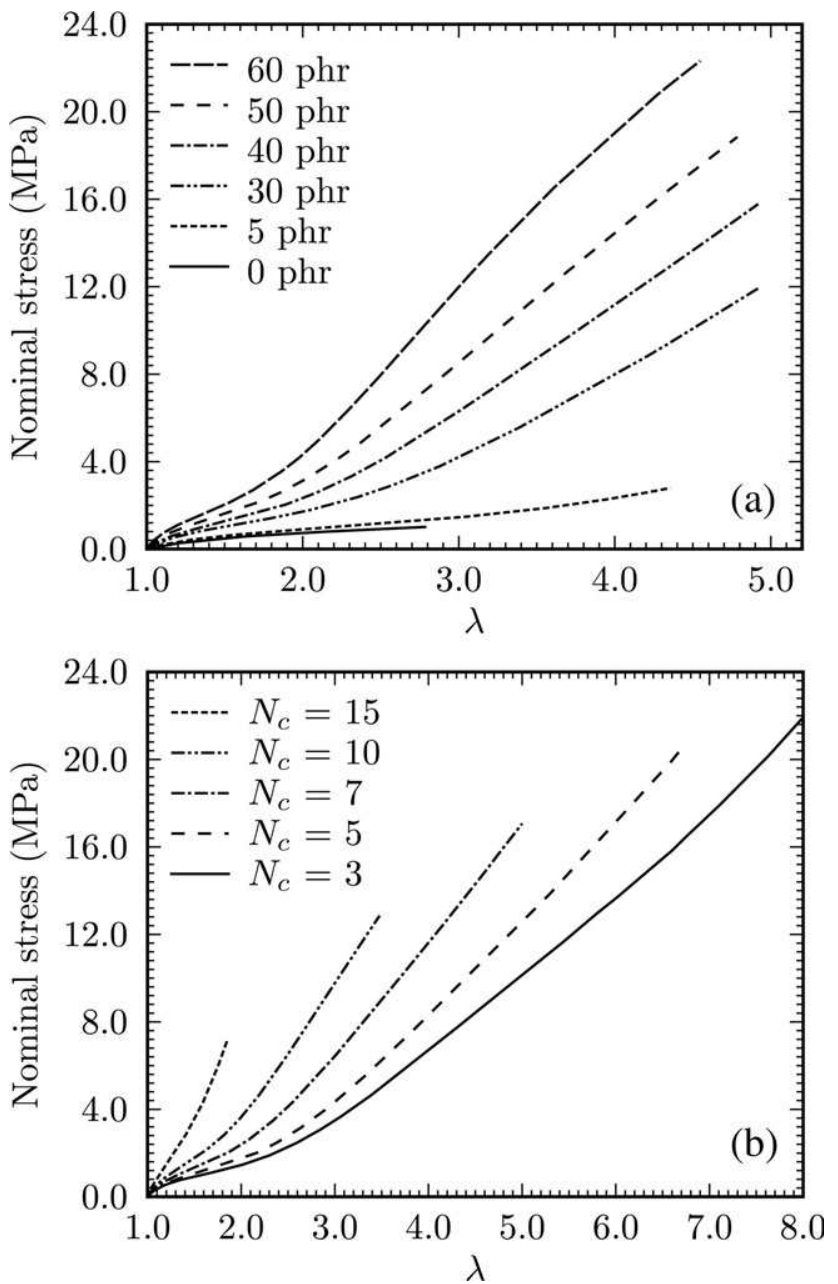

Figure 2. Stress-stretch responses to monotonic uniaxial tensile tests for (a) materials with various amount of fillers and similar crosslink density $\left(N_{c} \sim 7.0 \times 10^{-5} \mathrm{~mol} \mathrm{~cm}{ }^{-3}\right)$ and (b) materials with various crosslink densities and same amount of fillers (40 phr). of eqs. (1) and (2) against the experimental measures of Young modulus carried out on materials C1-C6. Figure 3(a) presents the comparison between the experimental data and the theoretical results. One may be satisfied with the comparison for volume fractions of fillers up to $17 \%(\sim 40 \mathrm{phr})$. Nonetheless, calculations provided by eqs. (1) and (2) are mostly phenomenological and lack physical understanding of the microstructure effect on the material reinforcement. Recent works ${ }^{13,14}$ show that filled rubbers may exhibit a layer of bounded rubber surrounding the fillers. Due to reduced chain mobility, the bounded rubber layer shows enhanced stiffness that contributes to the material reinforcement. Micromechanics modeling efforts ${ }^{15,16}$ demonstrate that the layer of bounded rubber should be taking into account in order to reach the modulus of filled elastomers in the rubbery state.

The dependence of the Young modulus to the crosslink density is presented in Figure 3(b), which compares the Young modulus of materials A4 to D4. These materials contain the same amount of fillers ( $40 \mathrm{phr})$ and crosslink densities range from 3 $\times 10^{-5}$ to $15 \times 10^{-5} \mathrm{~mol} \mathrm{~cm}{ }^{-3}$. The Young modulus is observed to increase with $N_{c}$. This result is consistent with previous studies. ${ }^{17-20}$ However, it seems that no analytical relation describing the Young modulus dependence to $N_{c}$ has been clearly established in the case of filled rubbers. According to the rubber elasticity statistical theory of affine networks, ${ }^{21}$ the Young modulus of an unfilled network is expected to be inversely proportional to its chain length and consequently proportional to the crosslink density. Therefore, for unfilled rubbers, the Young modulus is expected to be proportional to $N_{c}$. In filled rubbers this proportionality relation is not verified as shown in Figure 3(b).

\section{Damage}

While significantly stretched materials undergo some damage ending with the ultimate break of the sample. Part of this damage may result from cavitation and cavity growth that can be monitored by measuring the volume changes during the material stretching. Actually, substantial volume changes have been reported within filled rubbers when first stretched. ${ }^{22-25}$ The volume change may be attributed to decohesion at the filler-rubber interface and to vacuole formation in the rubber matrix. ${ }^{23,26} \mathrm{~A}$ review on the topic has been proposed in Ref. 27. Volume changes measured during stretching tests presented in Figure 2 appear in Figure 4. Similar volume changes were estimated on a partial set of our materials, measuring the volume fraction of voids by small angle X-ray scattering. ${ }^{28}$ The latter work assesses the source of the volume change as small void formation. Figure 4 shows substantial volume changes within filled rubbers. The 5 phr filled rubber may fairly be considered as incompressible but the other filled rubbers are far from being incompressible as it 

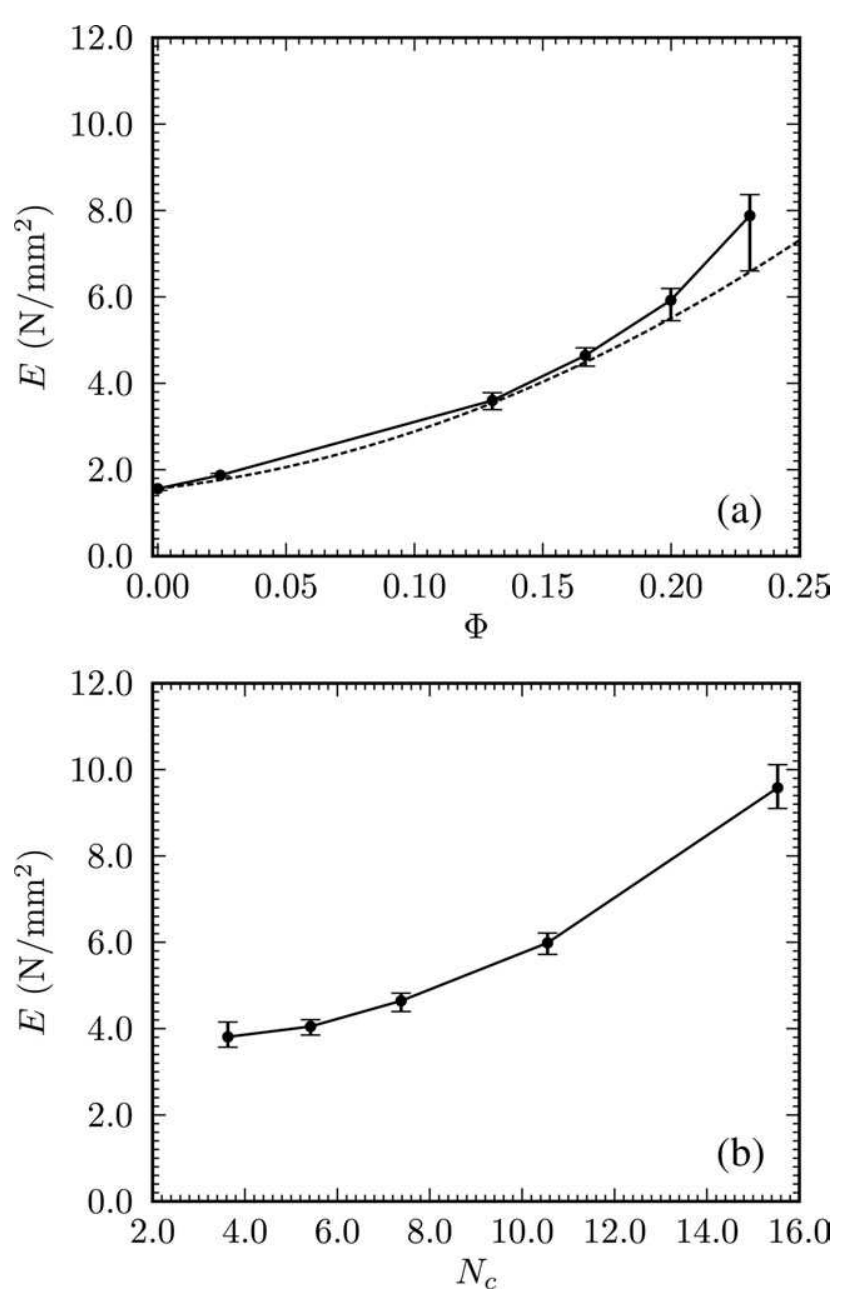

Figure 3. Dependence of material Young modulus (a) to the amount of fillers for materials with $N_{c} \sim 7.0 \times 10^{-5} \mathrm{~mol} \mathrm{~cm}^{-3}$ and (b) to the crosslink densities for materials with $40 \mathrm{phr}$ carbon-black.

is generally assumed. The volume expansion increases with the amount of fillers. One may notice that volume does not expand until material is stretched beyond a threshold depending on the amount of fillers. The stretch threshold of volume change decreases when increasing the amount of fillers. It was measured to approximately $2.7,3,3.5$, and 4.2 for materials C6, C5, C4, and $\mathrm{C} 3$, respectively. This result agrees with previous work. ${ }^{29} \mathrm{~A}$ more original result reads in Figure 4(b), which presents the volume changes of materials A4 to E4 that are filled with 40 phr and present different crosslink densities. Figure 4(b) shows that the crosslink density does not significantly affect the material volume changes. One notes that the volume change stretch threshold remain close to 3 for every material. Nonetheless, the stretch to failure is significantly affected by the crosslink density, which proves that it is difficult to draw a direct correlation between void volume fraction and stretch to failure in filled and unfilled rubbers.

Another evidence of damage observed in filled rubbers is a strong softening upon first stretch when cyclic loadings are applied. This softening, commonly referred as Mullins soften- ing, ${ }^{30}$ has been under investigation for six decades. Recently, the authors proposed an original parameter accounting for the Mullins softening. This parameter provides a quantitative measure of the Mullins softening. Results reported in Ref. 2 illustrate similar features of the effect of the material composition on the Mullins softening than the volume change features presented above. The volume changes and the Mullins softening both require a minimum amount of fillers to occur. Both effects are amplified with increasing the amount of fillers and neither one is significantly affected by the material crosslink density. However, the Mullins softening is observed before the appearance of cavities. Moreover the void volume fraction measured in filled rubbers is not large enough to explain the significant change in the mechanical properties due to the Mullins effect. Therefore, while cavitation may contribute to the Mullins softening, it is probably not the main cause.

\section{Stretch to Failure}

The failure of rubber materials is associated to catastrophic growth of cracks. It is generally admitted that the presence of fillers within the rubber gum acts as obstacles and stops or
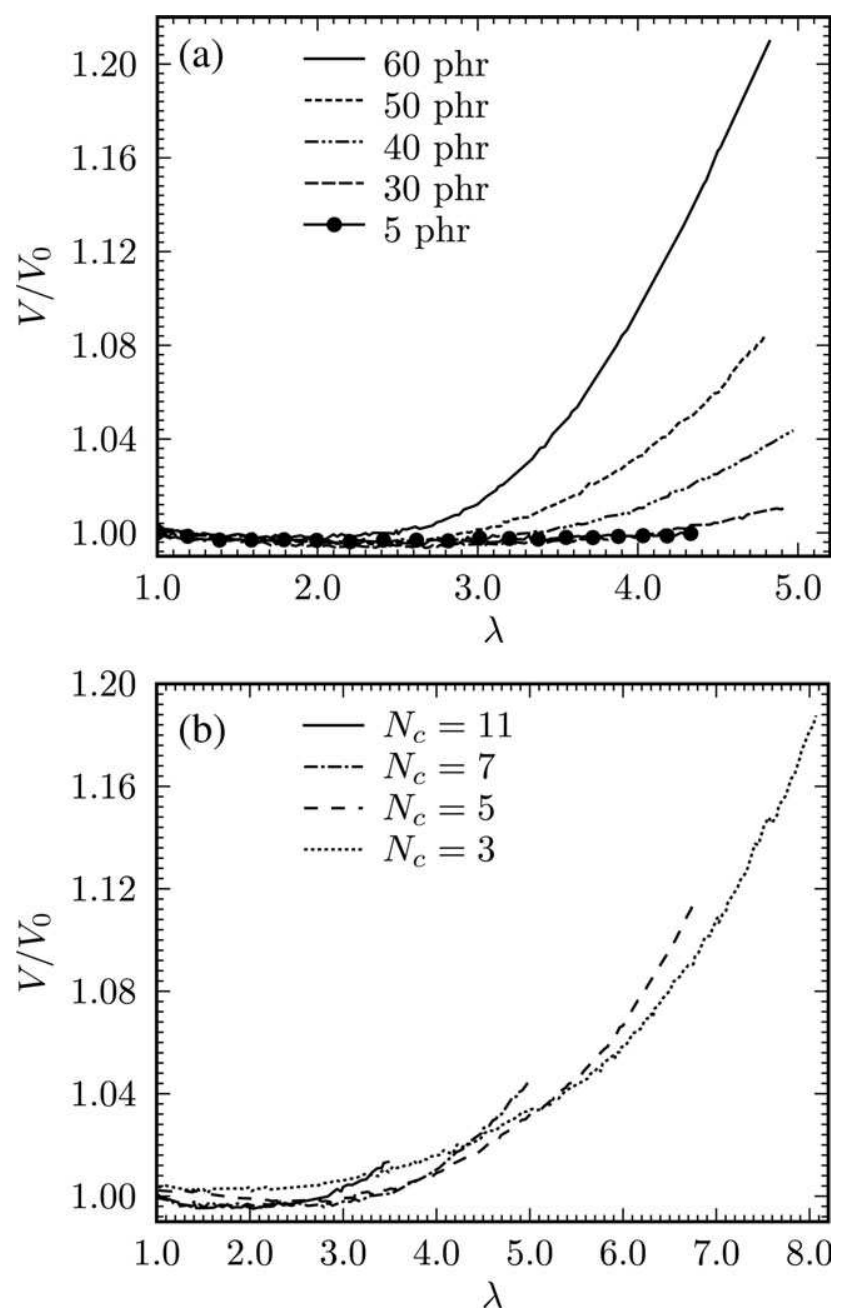

Figure 4. Volume changes occurring during uniaxial tests presented in Figure 2 (a) with respect to the amount of fillers and (b) with respect to the material crosslink density. 
reduces the crack growths and therefore delays the critical failure. Figure 5(a) shows the stretch to failure $\lambda_{\text {fail }}$ with respect to the amount of fillers obtained on materials $\mathrm{C1}-\mathrm{C} 6$. One notices that the presence of fillers improves the failure properties of the unfilled rubber. The stretch to failure shows an optimum for an amount of filler around $30 \mathrm{phr}$. Such results are supported by results from the literature showing the stretch to failure increasing with the amount of fillers for low amount of fillers ${ }^{2,9,31,32}$ then decreasing for larger amount of fillers., ${ }^{9,33}$ For large amounts of fillers, the carbon-black filler aggregates may agglomerate into larger clusters that contain defects from which cracks initiate and propagate more easily. ${ }^{2}$ We note that an optimal amount of fillers with respect to fatigue has been observed also. $^{3}$

Figure 5(b) illustrates the dependence of the stretch to failure to the crosslink density. Results show that the stretch to failure is strongly impacted by $N_{c}$. By increasing the crosslink density, one significantly decreases the stretch to failure. This observation is in good agreement with several results reported in the literature. ${ }^{17,19,34-38}$ However, authors did not define a relationship between the stretch to failure and the crosslink density for
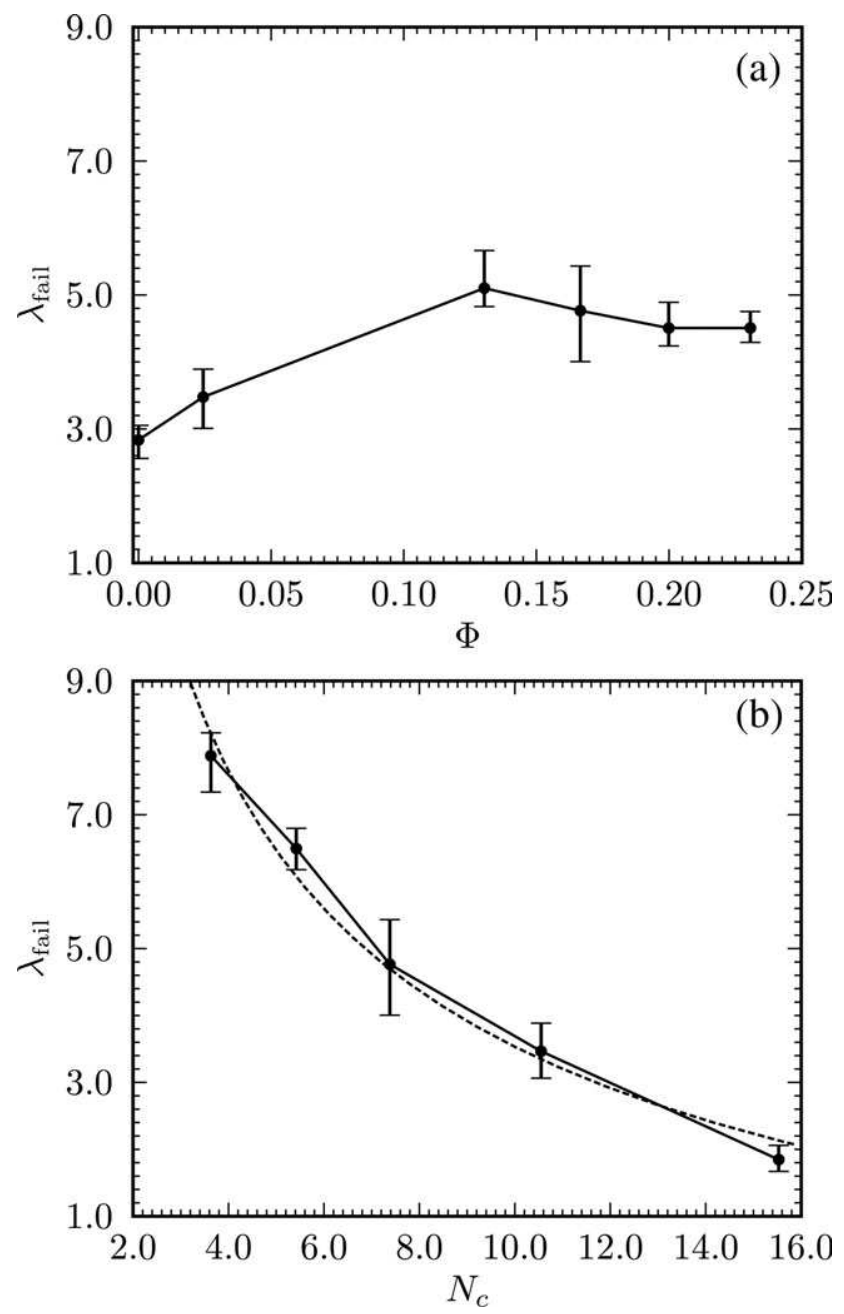

Figure 5. Effect of the amount of fillers (a) and of the crosslink density (b) on the uniaxial stretch to failure. filled rubbers. For unfilled rubbers, Bueche and Halpin ${ }^{34}$ proposed the proportional relation $\lambda_{\text {fail }} \propto N_{c}^{-1 / 2}$, which has been adopted in Ref. 39. The relation standing for unfilled rubbers is in accordance with the rubber elasticity statistical theory that describes the failure of a rubber network by the reach of its chain limit extensibility defined as the square root of the number of chain links. ${ }^{21}$ We tested the proportionality relation $\lambda_{\text {fail }} \propto N_{c}^{-1 / 2}$ on the experimental results of the $40 \mathrm{phr}$ filled rubbers (materials A4 to E4). Figure 5(b) shows the approximation of the experimental data by the equation $\left(0.068 N_{c}^{-1 / 2}-3.2\right)$ drawn in dashed line. This result assesses extension of the relation $\lambda_{\text {fail }} \propto N_{c}^{-1 / 2}$ to filled rubbers.

\section{CONCLUSIONS}

This contribution aimed at studying the effect of the filler volume fraction and the crosslink density on the mechanical behavior of SBR rubbers. For this purpose, several SBR filled with N347 carbon-black fillers were manufactured. Materials vary from each other in the amount of fillers or the crosslink density only. Their mechanical behaviors were estimated by applying monotonic uniaxial tension up to failure.

Results showed that for moderate amount of fillers ( $<40 \mathrm{phr}$ ), the Young modulus was well approximated by a mere quadratic expression of the effective volume fraction of fillers. Nonetheless, the phenomenological relation does not apply to large amount of fillers and lacks physical understanding. The increase of the Young modulus with respect to the crosslink density appeared larger than in unfilled rubbers for which a linear relation exists between $E$ and $N_{c}$ when the material behaves as an affine network. Volume change measures upon stretching put in light the filled rubbers substantial compressibility when monotonously stretched. The volume change was attributed to the appearance of cavities in the material since it matched the amount of cavities measured by others on the same materials. The volume of a filled rubber expands upon stretching once passed a stretch threshold that decreases with the amount of fillers. The volume changes increase with the increasing amount of fillers. The filled rubber volume changes appear as unaffected by the crosslink density. These results show some similarity with the impact of the amount of fillers and crosslink density on the Mullins softening, nevertheless it was observed that it is difficult to draw a direct link between the two phenomena since Mullins softening occurs also at stretches below the threshold of cavity appearance. Furthermore, it was not possible to link the amount of cavities with the stretch to failure measured in uniaxial tension. Adding fillers improves stretch to failure, with an existing optimum reinforcement. The crosslink density was shown to have a strong negative impact on the stretch to failure when increasing. More interestingly, it was possible to define for $40 \mathrm{phr}$ filled rubbers, a proportionality relationship between the stretch to failure and the inverse of the square root of the crosslink density $\left(N_{c}^{-1 / 2}\right)$ that was already applied to unfilled rubbers and that is now proposed for filled rubbers.

\section{ACKNOWLEDGMENTS}

This work was supported by the French "Agence Nationale de la Recherche” through project AMUFISE (MATEPRO 08-320101). 


\section{REFERENCES}

1. Kohls, D.; Beaucage, G. Curr. Opin. Solid State Mater. Sci. 2002, 6, 183.

2. Merckel, Y.; Diani, J.; Brieu, M.; Gilormini, P.; Caillard, J. J. Appl. Polym. Sci. 2012, 123, 1153.

3. Zhao, J.; Ghebremeskel, G. N. Rubber Chem. Technol. 2001, 74, 409.

4. Auer, E. E.; Doak, K. W.; Schaffner, I. J. Rubber World 1957, 135,876

5. Coran, A. Y. Polym. Sci. Eng. 1989, 17, 666.

6. Lake, G. J.; Thomas, A. G. Philos. Trans. R. Soc. London A 1967, 300, 108.

7. Mullins, L.; Tobin, N. J. Appl. Polym. Sci. 1965, 9, 2993.

8. Bergstrom, J. S.; Boyce, M. C. Rubber Chem. Technol. 1999, $72,633$.

9. Flandin, L.; Hiltner, A.; Baer, E. Polymer 2001, 42, 827.

10. Bokobza, L. Macromol. Mater. Eng. 2004, 289, 607.

11. Guth, E.; Gold, O. Phys. Rev. 1938, 53, 322.

12. Medalia, A. Rubber Chem. Tehcnol. 1969, 42, 339.

13. Berriot, J.; Lequeux, F.; Monner, L.; Montes, H.; Long, D.; Sotta, P. J. Non-Cryst. Solids 2002, 310, 719.

14. Léopoldès, J.; Barrès, C.; Leblanc, J. L.; Georget, P. J. Appl. Polym. Sci. 2004, 91, 577.

15. Alberola, N. D.; Mele, P. Polym. Eng. Sci. 1997, 37, 1712.

16. Diani, J.; Gilormini, P.; Merckel, Y.; Vion-Loisel, F. Mech. Mater. 2013. In Press.

17. Smith, T. L. Polym. Eng. Sci. 1977, 17, 129.

18. Diani, J.; Ortega A. M.; Gall, K.; Kasprzak, S.; Greenberg, A. R. J. Polym. Sci. Part B: Polym. Phys. 2008, 46, 1226.

19. Dijkhuis, K. A.; Noordermeer, J. W.; Dierkes, W. K. Eur. Polym. J. 2009, 45, 3302.

20. Fukahori, Y. Polymer 2010, 51, 1621.
21. Treloar, L. R. G. The Physics of Rubber Elasticity; Oxford University Press, 1975.

22. Holt, W.; McPherson, A. J. Res. Natl. Bur. Stand. 1936, 17, 657.

23. Jones H.; Yiengst, H. Rubber Chem. Technol. 1941, 14, 113.

24. Gee, G.; Stren, J.; Treloar, L. R. G. Trans. Faraday Soc. 1950, 46, 1101.

25. Mullins, L.; Tobin, N. Rubber Chem. Technol. 1957, 30, 555.

26. Ramier, J.; Chazeau, L.; Gauthier, C.; Stelandre, L.; Guy, L.; Peuvrel-Disdier, E. J. Mater. Sci. 2007, 42, 8130.

27. Le Cam, J. B. Rubber Chem. Technol. 2010, 83, 247.

28. Zhang, H.; Scholz, A. K.; de Crevoisier, J.; Vion-Loisel, F.; Besnard, G.; Hexemer, A.; Brown, H. R.; Kramer, E. J.; Creton, C. Macromolecules 2011, 45, 1529.

29. Shinomura, T.; Takahashi, M. Rubber Chem. Technol. 1970 $43,1025$.

30. Mullins, L. Rubber Chem. Technol. 1969, 42, 339.

31. Hamed, G. R. Rubber Chem. Technol. 1994, 67, 529.

32. Gauthier, C.; Chazeau, L.; Prasse, T.; Cavaillé, J. Y. Compos. Sci. Technol. 2005, 65, 335.

33. Krauss, G. Rubber Chem. Technol. 1971, 44, 199.

34. Bueche, F.; Halpin, J. C. J. Appl. Phys. 1964, 35, 36.

35. Smith, T. L.; Magnusson, A. B. J. Appl. Polym. Sci. 1961, 5, 218.

36. Fedors, R. F.; Landel, R. F. Rubber Chem. Technol. 1966, 39, 712.

37. Ortega, A. M.; Kasprzak, S. E.; Yakacki, C. M.; Diani, J.; Greenberg, A. R.; Gall, K. J. Appl. Polym. Sci. 2008, 110, 1559.

38. Wang, Q.; Wang, F.; Cheng, K. Rad. Phys. Chem. 2009, 78, 1001.

39. Smith, T. L. Rubber Chem. Technol. 1967, 40, 544. 